\title{
Flexible Carbon Based Nanoelectronics with Printing
}

\section{Approaches}

\author{
Prachi Soni $^{1 \text { (D) , Gagan Kant Tripathi }}{ }^{1, *}$, Priyavand Bundela ${ }^{1}$ (D), Pradeep Kumar Khiriya ${ }^{1}$ (D), Purnima \\ Swarup Khare ${ }^{1}$ iD
}

1 School of Nanotechnology, Rajiv Gandhi Proudyogiki Vishwavidyalaya (RGPV), India;

* Correspondence: gagankanttripathi@gmail.com (G.K.T.);

Scopus Author ID 56906709100

Received: 9.07.2021; Revised: 18.08.2021; Accepted: 22.08.2021; Published: 11.09.2021

\begin{abstract}
This review construes diverse upcoming technologies and significant physical concerns in polymer-carbon composite materials nanoelectronics. There are numerous cases from mechanically flexible and portable thin-film transistors based on carbon materials, flexible and stretchable energy storage applications, flexible sensors applications to flexible solar cells. In various systems, the mechanical structure design is as essential as circuit structure designing. Recent studies in flexible carbon materials-based nanoelectronics suggest that in addition to the advancement, multidisciplinary approaches such as $3 \mathrm{D}$ printing, incorporating almost every area of the conventional research, in materials science, chemistry, physics, and engineering fields such as electrical, electronic and mechanical.
\end{abstract}

Keywords: graphene; polymer nanocomposite; 3D printing; flexible nanoelectronics.

(c) 2021 by the authors. This article is an open-access article distributed under the terms and conditions of the Creative Commons Attribution (CC BY) license (https://creativecommons.org/licenses/by/4.0/).

\section{Introduction}

Advancement is the key to the next generation innovations, which takes place when we need to modify the current technology. This is because of the need to solve the problem and because of basic human nature. We have been working hard to expand and test the limits in a defined time frame. Our skills and scope of innovation are limited by the knowledge that we have gained. Through a clever interdisciplinary approach, with the help of existing fields, there are many opportunities to develop new scientific fields.

There is a growing call for in-growing sustainable manufacturing strategies that can permit an automated fabrication of a described quantity of products on call for, at a proportional cost of the traditional serial manufacturing routes. The benefit would be to make manufacturing the goods more sustainable, reducing the waste and minimizing the energy used. This will lead to a paragon shift in today's industry, in which advanced manufacturing technologies can create new large-scale manufacturing systems The number of publications on 3D printing of functional devices such as sensors and biomedical devices increases every year. In particular, 3D printing technology has serious advantages over existing technologies for manufacturing functional devices for energy storage in a small area to apply the biomedical field. These advantages are: (1) Create structures of any geometric shape, lateral extent, and thickness; (2) Controllable composition and properties of printed devices; (3) Due to the additive aspect of the process, low manufacturing costs, and less material waste is achieved. In addition, 3D 
printing shows remarkable applicability on flexible and curved substrates, such as plastic, paper, conductive films, etc.

Here in this review, we significantly discuss the techniques used to $3 \mathrm{D}$ print inks primarily based totally on solid-state materials, which are applicable for energy storage applications, which can be used in various applications such as implantable devices as well as health monitoring devices and the demanding situations withinside the field. Direct inks can be 3D printed for various materials, including ceramics, polymers, metals, and carbon materials such as graphene and carbon nanotubes. In particular, graphene-based materials have great advantages in energy storage applications due to their specific surface area, excellent elasticity, chemical stability, and exceptional electrical conductivity. The multi-material properties of this printing technology enable the complete printed devices to be easily unified with external electronics circuits, thereby minimizing the cost and intricacy of the fabrication process. Figure 1. shown below, represents the futuristic applications that can be realized with the help of $3 \mathrm{D}$ printing technology.

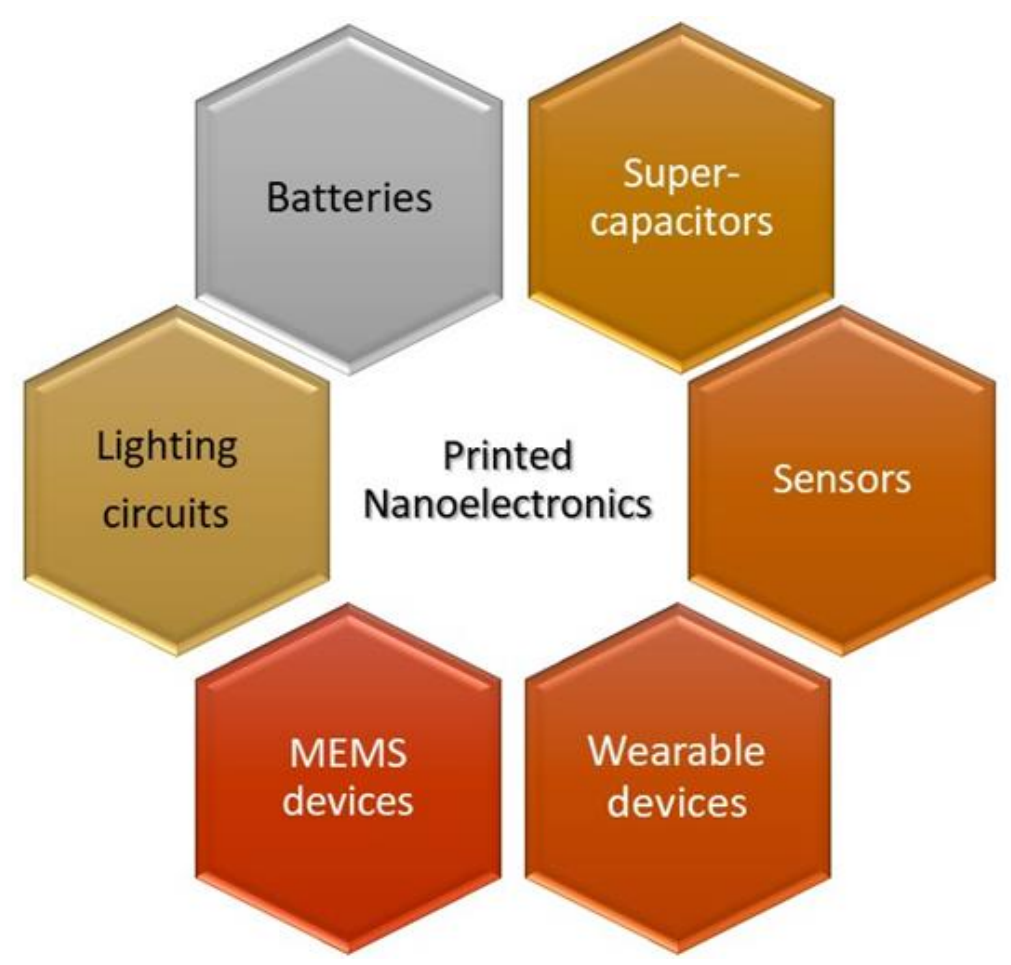

Figure 1. Applications of printed carbon-based nanoelectronics.

When the environment needed to pick a detail as the premise for life, it selected carbon. Pristine carbon takes place in numerous methods along with diamond, graphite, graphene, fullerene, and nanotubes, every allotrope of carbon has been a celebrity material its time;for example, diamond, which is the sp3 hybridized allotrope of carbon, became Science's molecule in the year 1988 due to the fact firstly, it was synthesized in the form of thin films with the aid of using chemical vapor deposition (CVD). The internal charge transfer properties and main points that restrict the "charge carrier mobility" vary drastically among all diverse carbon nano range structures, whereas the electronic property of structures and the attainable properties of the respective $\pi$-systems. Bonding among carbon and different elements can effortlessly be modified with the aid of using chemical and physical interactions. Polymer carbon nanoelectronics is a leading-edge study area with interdisciplinary research in materials science, nanotechnology, chemistry, physics, and engineering domains. With the advancement 
of polymer electronics, there was a huge interest in the characteristics of carbon-based substances because of the large amount of delocalization of fullerene's and carbon nanotubes (CNT) $\pi$-electron. The interest in nanoscale electronics is regularly increasing the work by the top to the down method into nanoscale structures. The role of the most reliable material, carbon nanostructures, both two-dimensional graphenes [1-2] as well as quasi-1D CNTs [3], has given an entirely new idea in the direction of carbon-based electronics devices. In various ways, CNTs feature the polymer chains utilized as composite matrices, each having covalently bonded structures, comparable properties, and mechanical flexibility. However, despite the fact that there's considerable attraction towards it in mixing little amount of CNT to polymer substances, the things that genuinely subjects are the capability to make suspension with them into the polymer base, i.e., the problem to isolate the agglomerated tubes, the sturdy faith of the CNT structure conductivity, as well as the limited strategies for analyzing its properties in liquid dispersion have decelerated the basic development in the usage of its strength in the field of nanotechnology. Through the current technological advancements in the area of nanopolymers, the blend of conventional polymers, and the growing area of nanotechnology, many interesting outcomes have been validated; those polymers packed with carbon-based substances have specific properties consisting of advanced energy and durability, electrical conductivity, UV absorption, flame resistance, as well as decreased permeability.

From the beginning of the 2000s, some of the researchers from industries and academia have explored the various opportunities for understanding flexible electronic device techniques, for example, synthetically tailored soft materials with variable electrical and electromagnetic behaviors [4]. Flexible device approaches bring an awful interest in electronics for flexible applications because the flexible devices can be bent and can be folded to any shape within a confined area as per necessity. For regulation needed for the latest technology would be in need of in-depth knowledge. Specifically, precious are the approaches that can develop charge and wave transportation in the polymers incorporating nano-fillers acknowledged to exclusive varieties of mechanical actions. Also, the basic requirement of this investigation is that this problem is truly of concern to researchers inquisitive about the multifunctionality working of nanostructures. Well, questions encompassing the tuning among the structural, mechanical, and electrical behavior of that material retain to have numerous analytical challenges. In this review, we intend to focus on the advancement of polymer carbon nanoelectronics by depicting numerous revealing examples. These examples can have some of the common properties; however, every property additionally has specific features, for example, some of the materials having some capability to be used in flexible electronic components consisting of high frequency, likely heterogeneously incorporated with the CMOS Silicon interfaces, whereas others subject to dc functions, such as photovoltaics. This domain has advanced via the findings of various research work.

\section{SWNT for flexible thin-film electronics}

Micro and nanoelectronics well-known approaches or 3D printing methods can be implemented to produce SWNT thin-films on Flexible substrates to fabricate electronic devices, like antennas, resonators, and digital logic circuits [5-6]. Moreover, some types of 3Dcrosslinked organic layers fabricated via self-assembly methods appeal to comprehend flexible electronics structures because of the huge capacitance, exceptional insulating properties, and fine surface capacities. Besides, those devices are the best of realistic value when incorporated into circuits. However, the SWNT's polarity may be controlled with the help of using charge- 
transfer doping techniques, a CMOS kind inverter, that is one of the essential electronic circuit components, which can be fabricated by the connection of a p-channel to the n-channel gate devices, by the doping of the oxygen as well as the polymers [5,7-10]. Transistor's mobilities that use coordinated SWNTs arrays, for which advancement is pushed via improvement of regulated growth strategies, have attained the values $\left(\approx 2000 \mathrm{~cm}^{2} \mathrm{~V}^{-1} \mathrm{~s}^{-1}\right)$ that evaluate nicely with few outstanding inorganic semiconductors. Simultaneously, analysis of the devices that utilize subjective networks thin films having the mobility (approx. hundred $\mathrm{cm}^{2} \mathrm{~V}^{-1} \mathrm{~s}^{-1}$ ) lots more than one of the organic semiconductors. In both thin-film forms, control over polarity can be executed by charge-transfer doping strategies, as examples with power-active CMOS digital logic circuits. Analog circuits, as well as complex functional circuits, consists of almost a hundred SWNT components and running at frequencies nicely in GHz system, were validated, displaying the SWNT thin-films approach's extensibility. Chimot et al. [11] have suggested "CNT/polyethyleneterephtalate (PET) transistors" having "current gain cut-off frequency" as good as $1 \mathrm{GHz}$ and steady $6 \mathrm{GHz}$ of maximum trans-conduction. It is additionally observing the extreme transportability and extinction of the bandgap rely on that the graphene could not be that much beneficial for the utilization in logic transistors that need to be turned off. However, it can be highly applicable to "high-frequency analog RF transistors". Additionally, we examine, as the size of the electronic devices reduces in the nano range, the function of electronics leads turns into highly essential emerging as an intrinsic part of its functional arrangement. The process flow diagram of the 3D printed SWCNT thin film transistor is shown in Figure 2 [12].
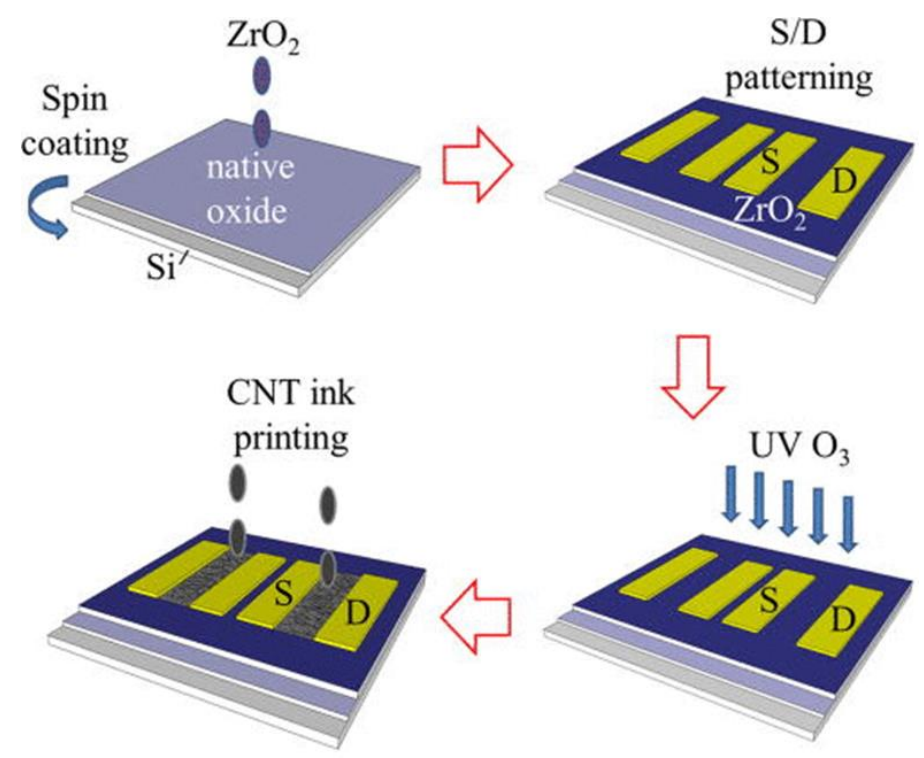

Figure 2. Process flow diagram of fabrication of 3D printed SWCNT thin film transistor.

\section{Carbon-based materials for flexible electronics}

3D Printing is proven to be a resourceful generation for the applications of electronic devices that the usual silicon technology can't manufacture. A hard silicon wafer is needed to fabricate "Single-crystal silicon micro-electronics" and are also confined into small areas. Polycrystalline and amorphous silicon can make broad-region devices, but they have very small carrier mobility and are generally confined to a hard substrate. Moreover, more than one lithographic process and high-vacuum methods in the cleanroom make the cost of silicon microelectronics devices notably much more. Whereas, the printing process of semiconductors, 
as well as metals, allows the advent of big region electronics devices on a flexible substrate, which allows extreme extent economies. The utilization of 3D printed nanoelectronics is numerous and prevalent, such as electronic devices, e. g. biosensors, electronics devices for implantable medical sensors, cheap sensors, etc. It is assumed that printed electronics will reform our way of life in the upcoming time simply as silicon microelectronics have accomplished in the previous decades. The biggest division of all the 3D printed electronics corporations is printed transistors as well as memory devices.

Printable inks consist of the maximum importance for 3D printing and are associated with the substances, the printing method, as well as the design structures of the 3D-printed devices. It is crucial for the ink materials to function with good viscosity and shear-thinning property to allow stable 3D prints. Because of the excellent chemical stability and flexibility of the nanostructures, carbon substances were widely utilized in $3 \mathrm{D}$ printing approaches. Carbon-based materials 3D printable inks are specifically synthesized in volatile aqueous solutions with carbon materials as fillers such as carbon nanotubes (CNT), carbon blacks, graphene oxide (GO), and a solvent addition polymers and various additives. CNTs and carbon black typically need the support of polymers to manage the viscosity [13] of the ink to obtain the right printability, and considerable research was reported on the utilization of the 3Dprinting method to manufacture exceptional devices such as batteries, supercapacitors, and also sensors. As correlated to CNTs and carbon black, GO is proven to be an appropriate printing competency with precise viscoelastic properties in an aqueous solution, in the absence of including polymers to govern the viscosity. If concentrations of GO are low, then GO inks show liquid-like properties that can't be appropriate for 3D printing. In the GO inks, which are highly concentrated, GO represents a gel-like property providing a very high elastic modulus so that it can be printed finely in the form of filaments and complicated 3D structures in the form of layers [13]. Graphene is a one-atom thin, 2D carbon material that shows a sequence of specific properties, such as large surface area, excellent mechanical properties, low density, thermal stability, and outstanding electric properties, and shows a promising scope in materials development [14].

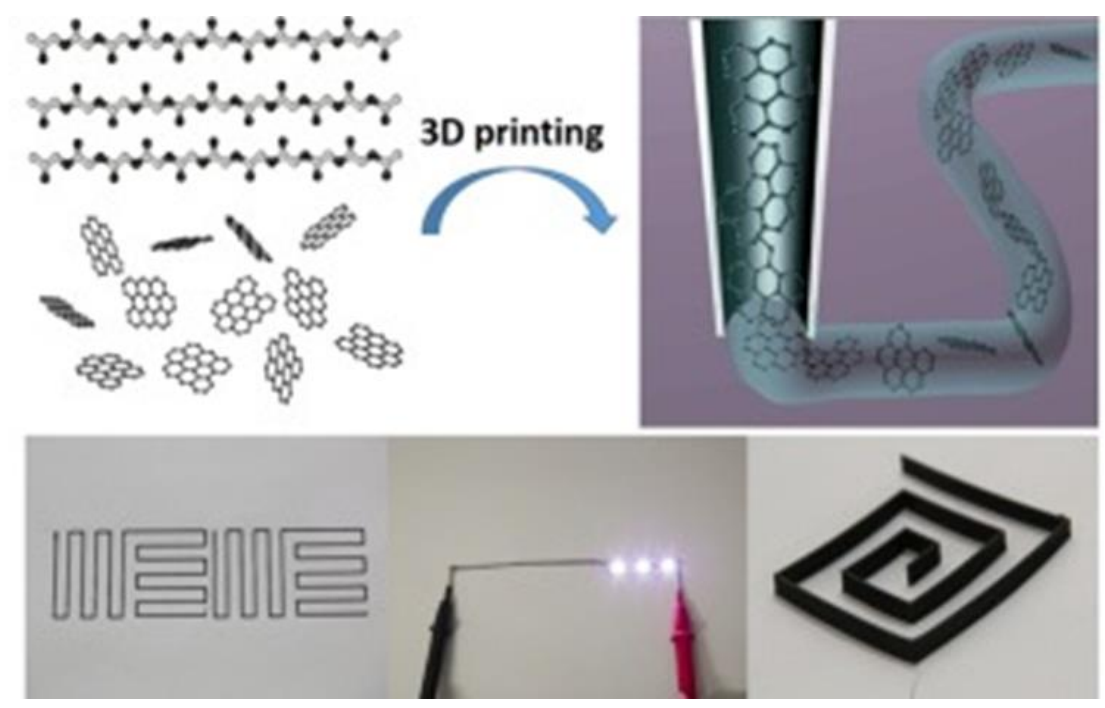

Figure 3. Illustration of 3D printed graphene electrodes.

As an essential variant of graphene, GO can be recognized as a resourceful transition through the alteration in its chemical properties to get a balanced system among graphene and their oxidation states that widens numerous applications [15]. They are extensively utilized in 
lots of applications, consisting of electrochemical energy storage devices [16-19], sensors [2021], electronics [22-23], catalysis [24-25], and composites, and biomedical applications [2627]. Exclusively, the specific structural capabilities of graphene collectively with GO enable them to be a perfect substance as building blocks or conducting polymer additives utilized in electrochemical energy storage devices, like supercapacitors and batteries [18-19].

\section{Wearable and portable electronics.}

Wearable and portable electronic materials have been the center of attraction for many researchers in various fields because of their large variety of applications [29-31]. The substrate performs an essential function when handling portable devices as it hosts several conductive, semiconducting, and insulating components. For this purpose, paper is a completely interesting substrate due to the myriad of feasible, relevant applications such as sensors [32-33], energy storage components [34-35], and electronic devices [36]. Many such applications appeal to the reality that paper is very much lightweight, globally available, biodegradable, biocompatible, and foldable, aside from the low-cost manufacturing [37-42]. Paper's foldable and portable functionality is likewise an exciting characteristic because it enables the fabrication of 3D printed electronic and electrochemical devices with specific properties. For example, currently, independent groups suggested that porous paper permits the formation of 3D conductive circuits connected by the substrate using polypyrrole/PEDOT: PSS [43-44] as a conducting medium. Including the conducting polymers, metallic nanostructures were currently utilized to make portable and flexible electronic devices on paper [45-46]. Carbon-based nanomaterials, including CNTs, graphene, and carbon black, are widely accepted for developing flexible electronic devices on paper because of their exceptional electrical and mechanical properties [46-48]. In the fabrication context, carbon-based nanomaterials are generally structured on paper through the utilization of wet transfer [49-50] and printing approaches [51-52]. Specifically, 3D printing is a trustworthy technique that permits huge area, low-cost, and scalable fabrication approaches[53]. Recently, numerous routes had been taken to make conductive circuits on paper focused on exceptional applications consisting of digital microfluidics [51], transistors [47], optoelectronics [50], and electrochemical devices [52]. Additionally, there may be a growing need for adaptable electronic paper-based electronic devices that can assist essential demands: (i) easy 3D printing approaches of carbon-based nanomaterials onto the paper, which can shape conductive circuit paths with comparatively little sheet resistance and good folding stability. (ii) Carbon-based electrodes with "large heterogeneous rate constants in flexible electrochemical cells". (iii) Tunable electrical and electronic properties with the purpose to achieve good enough overall performance and wearable and portable devices [53-72].

\section{Conclusions}

This review article shows the latest developments of Carbon matrix polymers for applications in various kinds of electronic, sensor, and optoelectronic devices. Devices that are based on the rising techniques of polymer-carbon composite nanoelectronics are flexible, portable, and foldable into different shapes, thus allowing the applications that might be very difficult to obtain through the utilization of the brittle, hard, and planar structure of today's electronics, such as Silicon or III-Vs. For the fabrication corresponding flexible along with 
strong electro-mechanical devices, various elements consisting of unique electrochemical and interfacial characteristics are required to get incorporated into each unit.

\section{Funding}

This research received no external funding.

\section{Acknowledgments}

This research has no acknowledgment.

\section{Conflicts of Interest}

The authors declare no conflict of interest.

\section{References}

1. Geim, A.K.; Novoselov, K.S. The rise of graphene. In: Nanoscience and technology: a collection of reviews from nature journals. World Scientific: 2010; pp. 11-19, https://doi.org/10.1142/9789814287005_0002.

2. Neto, A.C.; Guinea, F.; Peres, N.M.; Novoselov, K.S.; Geim, A.K. The electronic properties of graphene. Reviews of Modern Physics 2009, 81, https://doi.org/10.1103/RevModPhys.81.109.

3. Ijima, S. Helical microtubes of graphitic carbon. Nature 1991, 354, 56, https://doi.org/10.1038/354056a0.

4. Brosseau, C.; NDong, W.; Castel, V.; Youssef, J.B.; Vidal, A. Electromagnetomechanical coupling characteristics of plastoferrites. Journal of Applied Physics 2007, 102, https://doi.org/10.1063/1.2757200.

5. Cao, Q.; Rogers, J.A. Ultrathin films of single-walled carbon nanotubes for electronics and sensors: a review of fundamental and applied aspects. Advanced Materials 2009, 21, 29-53, https://doi.org/10.1002/adma.200801995.

6. Someya, T.; Sekitani, T.; Iba, S.; Kato, Y.; Kawaguchi, H.; Sakurai, T. A large-area, flexible pressure sensor matrix with organic field-effect transistors for artificial skin applications. Proceedings of the National Academy of Sciences 2004, 101, 9966-9970, https://doi.org/10.1073/pnas.0401918101.

7. Khang, D.-Y.; Jiang, H.; Huang, Y.; Rogers, J.A. A stretchable form of single-crystal silicon for highperformance electronics on rubber substrates. Science 2006, 311, 208-212, https://doi.org/10.1126/science.1121401.

8. Jiang, H.; Khang, D.-Y.; Song, J.; Sun, Y.; Huang, Y.; Rogers, J.A. Finite deformation mechanics in buckled thin films on compliant supports. Proceedings of the National Academy of Sciences 2007, 104, 15607-15612, https://doi.org/10.1073/pnas.0702927104.

9. Kocabas, C.; Kang, S.J.; Ozel, T.; Shim, M.; Rogers, J.A. Improved synthesis of aligned arrays of singlewalled carbon nanotubes and their implementation in thin film type transistors. The Journal of Physical Chemistry C 2007, 111, 17879-17886, https://doi.org/10.1021/jp071387w.

10. Sun, Y.; Rogers, J.A. Inorganic semiconductors for flexible electronics. Advanced Materials 2007, 19, 18971916, https://doi.org/10.1002/adma.200602223.

11. Derycke, V.; Auvray, S.; Borghetti, J.; Chung, C.-L.; Lefèvre, R.; Lopez-Bezanilla, A.; Nguyen, K.; Robert, G.; Schmidt, G.; Anghel, C. Carbon nanotube chemistry and assembly for electronic devices. Comptes Rendus Physique 2009, 10, 330-347, https://doi.org/10.1016/j.crhy.2009.05.006.

12. Kim, B.; Jang, S.; Prabhumirashi, P.L.; Geier, M.L.; Hersam, M.C.; Dodabalapur, A. Low voltage, high performance inkjet printed carbon nanotube transistors with solution processed $\mathrm{ZrO} 2$ gate insulator. Applied Physics Letters 2013, 103, https://doi.org/10.1063/1.4819465.

13. Naficy, S.; Jalili, R.; Aboutalebi, S.H.; Gorkin III, R.A.; Konstantinov, K.; Innis, P.C.; Spinks, G.M.; Poulin, P.; Wallace, G.G. Graphene oxide dispersions: tuning rheology to enable fabrication. Materials Horizons 2014, 1, 326-331, https://doi.org/10.1039/C3MH00144J.

14. Novoselov, K.S.; Fal, V.; Colombo, L.; Gellert, P.; Schwab, M.; Kim, K. A roadmap for graphene. nature 2012, 490, 192-200, https://doi.org/10.1038/nature11458.

15. Kim, F.; Cote, L.J.; Huang, J. Graphene oxide: surface activity and two-dimensional assembly. Advanced Materials 2010, 22, 1954-1958, https://doi.org/10.1002/adma.200903932.

16. Yoo, E.; Kim, J.; Hosono, E.; Zhou, H.-s.; Kudo, T.; Honma, I. Large reversible Li storage of graphene nanosheet families for use in rechargeable lithium ion batteries. Nano letters 2008, 8, 2277-2282, https://doi.org/10.1021/n1800957b.

17. Wang, X.; Zhi, L.; Müllen, K. Transparent, conductive graphene electrodes for dye-sensitized solar cells. Nano letters 2008, 8, 323-327, https://doi.org/10.1021/n1072838r. 
18. Chu, Y.; Shen, Y.; Guo, F.; Zhao, X.; Dong, Q.; Zhang, Q.; Li, W.; Chen, H.; Luo, Z.; Chen, L. Advanced characterizations of solid electrolyte interphases in lithium-ion batteries. Electrochemical Energy Reviews2020, 3, 187-219,https://doi.org/10.1007/s41918-019-00058-y.

19. Zheng, C.; Niu, S.; Lv, W.; Zhou, G.; Li, J.; Fan, S.; Deng, Y.; Pan, Z.; Li, B.; Kang, F. Propelling polysulfides transformation for high-rate and long-life lithium-sulfur batteries. Nano Energy 2017, 33, 306-312, https://doi.org/10.1016/j.nanoen.2017.01.040.

20. Schedin, F.; Geim, A.K.; Morozov, S.V.; Hill, E.; Blake, P.; Katsnelson, M.; Novoselov, K.S. Detection of individual gas molecules adsorbed on graphene. Nature materials 2007, 6, 652-655, https://doi.org/10.1038/nmat1967.

21. Shao, Y.; Wang, J.; Wu, H.; Liu, J.; Aksay, I.A.; Lin, Y. Graphene based electrochemical sensors and biosensors: a review. Electroanalysis: An International Journal Devoted to Fundamental and Practical Aspects of Electroanalysis 2010, 22, 1027-1036, https://doi.org/10.1002/elan.200900571.

22. Eda, G.; Chhowalla, M. Graphene-based composite thin films for electronics. Nano letters 2009, 9, 814-818, https://doi.org/10.1021/nl8035367.

23. Eda, G.; Fanchini, G.; Chhowalla, M. Large-area ultrathin films of reduced graphene oxide as a transparent and flexible electronic material. Nature nanotechnology 2008, 3, 270-274, https://doi.org/10.1038/nnano.2008.83.

24. Machado, B.F.; Serp, P. Graphene-based materials for catalysis. Catalysis Science \& Technology 2012, 2 , 54-75, https://doi.org/10.1039/C1CY00361E.

25. Sutter, P.W.; Flege, J.-I.; Sutter, E.A. Epitaxial graphene on ruthenium. Nature materials 2008, 7, 406-411, https://doi.org/10.1038/nmat2166.

26. Hadjizadeh, A.; Doillon, C.J. Directional migration of endothelial cells towards angiogenesis using polymer fibres in a 3D co-culture system. Journal of tissue engineering and regenerative medicine 2010, 4, 524-531, https://doi.org/10.1002/term.269.

27. Zhu, C.; Han, T.Y.-J.; Duoss, E.B.; Golobic, A.M.; Kuntz, J.D.; Spadaccini, C.M.; Worsley, M.A. Highly compressible 3D periodic graphene aerogel microlattices. Nature communications 2015, 6, 1-8, https://doi.org/10.1038/ncomms7962.

28. Zhang, D.; Chi, B.; Li, B.; Gao, Z.; Du, Y.; Guo, J.; Wei, J. Fabrication of highly conductive graphene flexible circuits by 3D printing. Synthetic metals 2016, 217, 79-86, https://doi.org/10.1016/j.synthmet.2016.03.014.

29. LeMieux, M.C.; Bao, Z. Stretching our imagination. Nature nanotechnology 2008, 3, 585-586, https://doi.org/10.1038/nnano.2008.296.

30. Bandodkar, A.J.; Jeerapan, I.; You, J.-M.; Nuñez-Flores, R.; Wang, J. Highly stretchable fully-printed CNTbased electrochemical sensors and biofuel cells: Combining intrinsic and design-induced stretchability. Nano letters 2016, 16, 721-727, https://doi.org/10.1021/acs.nanolett.5b04549.

31. Huang, Y.; Bai, X.; Zhou, M.; Liao, S.; Yu, Z.; Wang, Y.; Wu, H. Large-scale spinning of silver nanofibers as flexible and reliable conductors. Nano letters 2016, 16, 5846-5851, https://doi.org/10.1021/acs.nanolett.6b02654.

32. Santhiago, M.; Strauss, M.; Pereira, M.P.; Chagas, A.S.; Bufon, C.C. Direct drawing method of graphite onto paper for high-performance flexible electrochemical sensors. ACS applied materials \& interfaces 2017, 9, 11959-11966, https://doi.org/10.1021/acsami.6b15646.

33. Große, S.; Wilke, P.; Börner, H.G. Easy Access to Functional Patterns on Cellulose Paper by Combining Laser Printing and Material-Specific Peptide Adsorption. Angewandte Chemie International Edition 2016, 55, 11266-11270, https://doi.org/10.1002/anie.201601603.

34. Nyholm, L.; Nyström, G.; Mihranyan, A.; Strømme, M. Toward flexible polymer and paper-based energy storage devices. Advanced Materials 2011, 23, 3751-3769, https://doi.org/10.1002/adma.201004134.

35. Yuan, L.; Xiao, X.; Ding, T.; Zhong, J.; Zhang, X.; Shen, Y.; Hu, B.; Huang, Y.; Zhou, J.; Wang, Z.L. Paperbased supercapacitors for self-powered nanosystems. Angewandte Chemie International Edition 2012, 51, 4934-4938, https://doi.org/10.1002/anie.201109142.

36. Russo, A.; Ahn, B.Y.; Adams, J.J.; Duoss, E.B.; Bernhard, J.T.; Lewis, J.A. Pen-on-paper flexible electronics. Advanced Materials 2011, 23, 3426-3430, https://doi.org/10.1002/adma.201101328.

37. Santhiago, M.; Henry, C.S.; Kubota, L.T. Low cost, simple three dimensional electrochemical paper-based analytical device for determination of p-nitrophenol. Electrochimica Acta 2014, 130, 771-777, https://doi.org/10.1016/j.electacta.2014.03.109.

38. Shiroma, L.Y.; Santhiago, M.; Gobbi, A.L.; Kubota, L.T. Separation and electrochemical detection of paracetamol and 4-aminophenol in a paper-based microfluidic device. Analytica chimica acta 2012, 725, 4450, https://doi.org/10.1016/j.electacta.2014.03.109.

39. Santhiago, M.; Wydallis, J.B.; Kubota, L.T.; Henry, C.S. Construction and electrochemical characterization of microelectrodes for improved sensitivity in paper-based analytical devices. Analytical chemistry 2013, 85, 5233-5239, https://doi.org/10.1021/ac400728y.

40. Santhiago, M.; Kubota, L.T. A new approach for paper-based analytical devices with electrochemical detection based on graphite pencil electrodes. Sensors and Actuators B: Chemical 2013, 177, 224-230, https://doi.org/10.1016/j.snb.2012.11.002. 
41. Renault, C.; Li, X.; Fosdick, S.E.; Crooks, R.M. Hollow-channel paper analytical devices. Analytical chemistry 2013, 85, 7976-7979, https://doi.org/10.1021/ac401786h.

42. Mettakoonpitak, J.; Boehle, K.; Nantaphol, S.; Teengam, P.; Adkins, J.A.; Srisa-Art, M.; Henry, C.S. Electrochemistry on paper-based analytical devices: a review. Electroanalysis 2016, 28, 1420-1436, https://doi.org/10.1002/elan.201501143.

43. Santhiago, M.; Bettini, J.; Araújo, S.R.; Bufon, C.C. Three-dimensional organic conductive networks embedded in paper for flexible and foldable devices. ACS applied materials \& interfaces 2016, 8, 1066110664, https://doi.org/10.1021/acsami.6b02589.

44. Hamedi, M.M.; Ainla, A.; Güder, F.; Christodouleas, D.C.; Fernández-Abedul, M.T.; Whitesides, G.M. Integrating electronics and microfluidics on paper. Advanced Materials 2016, 28, 5054-5063, https://doi.org/10.1002/adma.201505823.

45. Jason, N.N.; Shen, W.; Cheng, W. Copper nanowires as conductive ink for low-cost draw-on electronics. ACS applied materials \& interfaces 2015, 7, 16760-16766, https://doi.org/10.1021/acsami.5b04522.

46. Hyun, W.J.; Park, O.O.; Chin, B.D. Foldable graphene electronic circuits based on paper substrates. Advanced Materials 2013, 25, 4729-4734, https://doi.org/10.1002/adma.201302063.

47. Hyun, W.J.; Secor, E.B.; Rojas, G.A.; Hersam, M.C.; Francis, L.F.; Frisbie, C.D. All-printed, foldable organic thin-film transistors on glassine paper. Advanced Materials 2015, 27, 7058-7064, https://doi.org/10.1002/adma.201503478.

48. Cheng, Q.; Song, Z.; Ma, T.; Smith, B.B.; Tang, R.; Yu, H.; Jiang, H.; Chan, C.K. Folding paper-based lithium-ion batteries for higher areal energy densities. Nano letters 2013, 13, 4969-4974, https://doi.org/10.1021/n14030374.

49. Baptista-Pires, L.; Mayorga-Martínez, C.C.; Medina-Sánchez, M.; Montón, H.; Merkoçi, A. Water activated graphene oxide transfer using wax printed membranes for fast patterning of a touch sensitive device. ACS nano 2016, 10, 853-860, https://doi.org/10.1021/acsnano.5b05963.

50. Polat, E.O.; Uzlu, H.B.; Balci, O.; Kakenov, N.; Kovalska, E.; Kocabas, C. Graphene-enabled optoelectronics on paper. Acs Photonics 2016, 3, 964-971, https://doi.org/10.1021/acsphotonics.6b00017.

51. Ko, H.; Lee, J.; Kim, Y.; Lee, B.; Jung, C.H.; Choi, J.H.; Kwon, O.S.; Shin, K. Active digital microfluidic paper chips with inkjet-printed patterned electrodes. Advanced Materials 2014, 26, 2335-2340, https://doi.org/10.1002/adma.201305014.

52. Das, S.R.; Nian, Q.; Cargill, A.A.; Hondred, J.A.; Ding, S.; Saei, M.; Cheng, G.J.; Claussen, J.C. 3D nanostructured inkjet printed graphene via UV-pulsed laser irradiation enables paper-based electronics and electrochemical devices. Nanoscale 2016, 8, 15870-15879, https://doi.org/10.1039/C6NR04310K.

53. Bao, Z.; Chen, X. Flexible and Stretchable Devices. Advanced Materials 2016, 28, 4177-4179, https://doi.org/10.1002/adma.201601422.

54. Tripathi, G.K.; Rathore, H.; Chavali, M.; Rathore, D. Nanotechnology for Mitigating Impact of COVID-19. Journal of Applied Science, Engineering, Technology, and Education 2021, 3, 171-180, https://doi.org/10.35877/454RI.asci151.

55. Vyas, R.; Navin, K.; Tripathi, G.K.; Kurchania, R. Structural, magnetic, photocatalytic, and electrochemical studies of the mesoporous Nickel oxide (NiO) nanostructures. Optik 2021, 231, https://doi.org/10.1016/j.ijleo.2021.166433.

56. Tripathi, G.K. Engineered Nanomaterials and TheirProperties: A Review. Biosci. Biotech. Res. Comm 2019, 12, 764-771, https://doi.org/10.21786/bbrc/12.3/32.

57. Tripathi, G.K.; Kurchania, R. Photocatalytic behavior of $\mathrm{BiOX}$ (X= Cl/Br, $\mathrm{Cl} / \mathrm{I}$ and $\mathrm{Br} / \mathrm{I})$ composites/heterogeneous nanostructures with organic dye. Optical and Quantum Electronics 2017, 49, https://doi.org/10.1007/s11082-017-1042-3.

58. Tripathi, G.K.; Sharma, I.; Kant, C.; Pandey, R.R.; Saini, K.; Kurchania, R. Characterization of the photocatalytic activity of bismuth oxychloride nanostructures. Analytical Letters 2016, 49, 1452-1466, https://doi.org/10.1080/00032719.2015.1104324.

59. Tripathi, G.K.; Kurchania, R. Effect of doping on structural, optical and photocatalytic properties of bismuth oxychloride nanomaterials. Journal of Materials Science: Materials in Electronics 2016, 27, 5079-5088, https://doi.org/10.1007/s10854-016-4398-4.

60. Sharma, I.; Tripathi, G.K.; Sharma, V.K.; Tripathi, S.N.; Kurchania, R.; Kant, C.; Sharma, A.K.; Saini, K. One-pot synthesis of three bismuth oxyhalides $(\mathrm{BiOCl}, \mathrm{BiOBr}, \mathrm{BiOI})$ and their photocatalytic properties in three different exposure conditions. Cogent Chemistry 2015, 1 , https://doi.org/10.1080/23312009.2015.1076371.

61. Tripathi, G.K.; Saini, K.; Kurchania, R. Synthesis of nanoplate bismuth oxychloride — a visible light active material. Optics and Spectroscopy 2015, 119, 656-663, https://doi.org/10.1134/S0030400X15100136.

62. Srivastava, P.; Jaiswal, N.K.; Tripathi, G.K. Chlorine sensing properties of zigzag boron nitride nanoribbons. Solid State Communications 2014, 185, 41-46, https://doi.org/10.1016/j.ssc.2014.01.009.

63. Tripathi, G.K.; Pandey, R.R.; Kant, C.; Khare, P.S.; Saini, K. Synthesis of visible light active biocl photocatalyst for energy and environmental applications. Synthesis 2012, 3, 167-170.

64. Li, H.; Ma, Y.; Huang, Y. Material innovation and mechanics design for substrates and encapsulation of flexible electronics: a review. Materials Horizons 2021, 8, 383-400,https://doi.org/10.1039/D0MH00483A. 
65. Ravandi, S.; Minenkov, A.; Mardare, C.C.; Kollender, J.P.; Groiss, H.; Hassel, A.W.; Mardare, A.I. GalliumEnhanced Aluminum and Copper Electromigration Performance for Flexible Electronics. ACS applied materials \& interfaces 2021, 13, 6960-6974, https://doi.org/10.1021/acsami.0c22211.

66. Liu, L.; Shen, Z.; Zhang, X.; Ma, H. Highly conductive graphene/carbon black screen printing inks for flexible electronics. Journal of Colloid and Interface Science 2021, 582, 12-21, https://doi.org/10.1016/j.jcis.2020.07.106.

67. Yin, L.; Scharf, J.; Ma, J.; Doux, J.-M.; Redquest, C.; Le, V.L.; Yin, Y.; Ortega, J.; Wei, X.; Wang, J. High performance printed $\mathrm{AgO}-\mathrm{Zn}$ rechargeable battery for flexible electronics. Joule 2021, 5, 228-248, https://doi.org/10.1016/j.joule.2020.11.008.

68. Guo, J.; Yu, Y.; Cai, L.; Wang, Y.; Shi, K.; Shang, L.; Pan, J.; Zhao, Y. Microfluidics for flexible electronics. Materials Today 2021, 44, 105-135,https://doi.org/10.1016/j.mattod.2020.08.017.

69. Xu, J.; Guo, H.; Ding, H.; Wang, Q.; Tang, Z.; Li, Z.; Sun, G. Printable and recyclable conductive ink based on a liquid metal with excellent surface wettability for flexible electronics. ACS applied materials \& interfaces 2021, 13, 7443-7452, https://doi.org/10.1021/acsami.0c20549.

70. Righini, G.C.; Krzak, J.; Lukowiak, A.; Macrelli, G.; Varas, S.; Ferrari, M. From flexible electronics to flexible photonics: A brief overview. Optical Materials 2021, 115, https://doi.org/10.1016/j.optmat.2021.111011.

71. Li, Z.; Cui, Y.; Zhong, J. Recent advances in nanogenerators-based flexible electronics for electro-mechanical biomonitoring. Biosensors and Bioelectronics 2021, 186,https://doi.org/10.1016/j.bios.2021.113290.

72. Rodriguez, R.D.; Shchadenko, S.; Murastov, G.; Lipovka, A.; Fatkullin, M.; Petrov, I.; Tran, T.H.; Khalelov, A.; Saqib, M.; Villa, N.E. Ultra-Robust Flexible Electronics by Laser-Driven Polymer-Nanomaterials Integration. Advanced Functional Materials 2021, 31, https://doi.org/10.1002/adfm.202008818. 